\title{
Effect of Solvent Choice on the Self-Assembly Properties of a Diphenylalanine Amphiphile Stabilized by an Ion Pair
}

\author{
Enric Mayans, ${ }^{[a, b]}{ }^{b e m a ~ B a l l a n o},{ }^{[c]}$ Javier Sendros, ${ }^{[a, b]}{ }^{[b e r c ̧ e ̀ ~ F o n t-B a r d i a, ~}{ }^{[d, e]}$ \\ J. Lourdes Campos, ${ }^{[a]}$ Jordi Puiggalí, ${ }^{[a, b]}$ Carlos Cativiela, ${ }^{*[c]}$ and Carlos Alemán ${ }^{*[a, b]}$
}

\begin{abstract}
A diphenylalanine (FF) amphiphile blocked at the $\mathrm{C}$ terminus with a benzyl ester (OBzl) and stabilized at the $\mathrm{N}$ terminus with a trifluoroacetate (TFA) anion was synthetized and characterized. Aggregation of peptide molecules was studied by considering a peptide solution in an organic solvent and adding pure water, a $\mathrm{KCl}$ solution, or another organic solvent as co-solvent. The choice of the organic solvent and co-solvent and the solvent/co-solvent ratio allowed the mixture to be tuned by modulating the polarity, the ionic strength, and the peptide concentration. Differences in the properties of the media used to dissolve the peptides resulted in the formation of different
\end{abstract}

self-assembled microstructures (e.g. fibers, branched-like structures, plates, and spherulites). Furthermore, crystals of TFA.FFOBzl were obtained from the aqueous peptide solutions for $X$ ray diffraction analysis. The results revealed a hydrophilic core constituted by carboxylate (from TFA), ester, and amide groups, and the core was found to be surrounded by a hydrophobic crown with ten aromatic rings. This segregated organization explains the assemblies observed in the different solvent mixtures as a function of the environmental polarity, ionic strength, and peptide concentration.

\section{Introduction}

In their pioneering work, Reches and Gazit ${ }^{[1]}$ demonstrated the formation of diphenylalanine ( $F F$, for which $F=L-P h e)$ nanotubes in aqueous solution; these nanotubes were formed due to the directionality offered by a combination of hydrogen bonding and repeated phenyl stacking interactions. In subse-

\footnotetext{
[a] E. Mayans, J. Sendros, Dr. J. L. Campos, Prof. Dr. J. Puiggalí,

Prof. Dr. C. Alemán

Departament d'Enginyeria Química

Universitat Politècnica de Catalunya

EEBE, Edifici I.2, C/ Eduard Maristany, 10-14, 08019 Barcelona (Spain)

E-mail:jordi.puiggali@upc.edu

carlos.aleman@upc.edu

[b] E. Mayans, J. Sendros, Prof. Dr. J. Puiggalí, Prof. Dr. C. Alemán Barcelona Research Center for Multiscale Science and Engineering Universitat Politècnica de Catalunya

C/ Eduard Maristany, 10-14, 08019 Barcelona (Spain)

E-mail:jordi.puiggali@upc.edu

carlos.aleman@upc.edu

[c] Dr. G. Ballano, Prof. Dr. C. Cativiela

Department of Organic Chemistry and Instituto de Síntesis Quimica y Catalisis Homogenea (ISQCH)

University of Zaragoza-CSIC

50009 Zaragoza (Spain)

E-mail: cativiela@unizar.es

[d] Dr. M. Font-Bardia

Departament de Mineralogia, Cristallografia i Depòsits Minerals Universitat de Barcelona

Facultat de Geologia, c/Martí i Franquès, 08028 Barcelona(Spain)

[e] Dr. M. Font-Bardia

Unitat de Difracció de Raigs X, Centre Científic y Tecnològic

Universitat de Barcelona

C/Solé i Sabarís 1, 08028 Barcelona (Spain)

$\square$ Supporting Information and the ORCID identification number(s) for the

(iD)

author(s) of this article can be found under:

https://doi.org/10.1002/cphc.201700180.
}

quent studies, FF was proven as a minimal sequence that formed self-assembled peptide nanostructures, ${ }^{[2-8]}$ and this gave way to the development of a new class of biomaterials that are based on the addition of various $\mathrm{N}$ - and $\mathrm{C}$-terminal capping groups to aromatic FF or that are based on chemical modification of the $F$ residues.

The peptide amphiphile Fmoc-FF (Fmoc=9-fluorenylmethoxycarbonyl), which forms stable gels, is among the most studied FF-based biomaterials. Thus, Fmoc-FF gels with a variety of properties have been prepared by using different approaches. ${ }^{[9]}$ Gazit and co-workers formed gels by dissolving Fmoc-FF in an appropriate water-miscible solvent, ${ }^{[10,11]}$ whereas Ulijn and co-workers used a $\mathrm{pH}$-switch approach coupled with changes in the temperature to yield Fmoc-FF gels with variable properties (i.e. depending on the rate of decrease in the $\mathrm{pH}$ and the final $\mathrm{pH})^{[12-15]}$ The mixing method was also used by other groups, and it was shown that the mechanical properties of Fmoc-FF gels depended on the final ratio of dimethyl sulfoxide (DMSO) to water. ${ }^{[16,17]}$ More recently, Adams and coworkers formed Fmoc-FF gels by dissolving the peptide in an organic solvent (OS) and adding water, and the rheological properties depended on the choice of the OS. ${ }^{[18]}$ Furthermore, gels formed by using acetone were metastable and single crystals suitable for X-ray diffraction were collected. The structure showed parallel stacking of the Fmoc-FF molecules with the neighboring molecules interacting through hydrogen bonds and weak offset $\pi-\pi$ interactions. ${ }^{[18]}$ Similarly, studies on NapFF (Nap = naphthalene) and Cbz-FF ( $\mathrm{Cbz}=$ benzyloxycarbonyl) hydrogels evidenced fibrous structures made of $\beta$-sheet arrangements, even though the fibril dimensions depended on the aromatic capping group. ${ }^{[19]}$ Interestingly, the Fmoc-FF-OFm 
peptide, capped with Fmoc and 9-fluorenylmethyl ester (OFm) groups at the $\mathrm{N}$ and $\mathrm{C}$ terminals, respectively, exhibited a great variety of polymorphic microstructures (e.g. doughnut, stacked braids, dendritic, and microtubes) depending on the solvents used to promote the self-assembly. ${ }^{[20]}$ Notably, stacking interactions play a dominant role in such highly aromatic peptides.

An alternative approach is the chemical modification of the $F$ residues. Reches and Gazit ${ }^{[5]}$ explored the self-assembly of FF-based dipeptides in which the phenyl side chains were modified by halogen atoms, additional phenyl groups, or nitro substitutions. These homoaromatic dipeptide motifs formed tubular, spherical, and fibrillary structures in the nanoscale, and in some cases, nanocrystals and 2D nanoplates were also detected. These results proved that the properties of FF-based biomaterials could be properly tailored by engineering the $F$ residue.

Another investigated strategy is the co-assembly of FFbased biomaterials with other molecules bearing aromatic groups. ${ }^{[15,21-23]}$ This approach, which may provide intermolecular transfer mechanisms, ${ }^{[24,25]}$ was applied to the Npm-FF $\left(\mathrm{Npm}=\right.$ naphthoxymethyl) donor/dansyl acceptor system. ${ }^{[21]}$ Peptide fibers based partly on aromatic stacking interactions with the dansyl component intercalated within this structure exhibited a redshift in the fluorescence emission and corresponding quenching of the emission associated with the donor species. ${ }^{[21]}$ Besides, hydrogels derived from the co-assembly of Fmoc-FF and Fmoc-diglycine ${ }^{[22]}$ (Fmoc-GG) or FmocArg-Gly-Asp (Fmoc-RGD) ${ }^{[15]}$ showed higher elastic moduli than Fmoc-FF alone, whereas the combination of Fmoc-FF with Fmoc-Lys (Fmoc-K), Fmoc-Ser (Fmoc-S), or Fmoc-Asp (Fmoc-D) resulted in significant changes in the rheological properties and fiber morphology. ${ }^{[23]}$

Besides, solvent-induced structural transitions have been examined by different authors. Li and co-workers ${ }^{[26]}$ reported the transition of an organogel obtained by self-assembly of FF in toluene into a lower-like microcrystal merely by introducing ethanol as a co-solvent. Huang et al. ${ }^{[27]}$ reported the structural transition of self-assembled FF from microtubes into nanofibers by introducing acetonitrile as a co-solvent in the water phase. Kumaraswamy et al. ${ }^{[28]}$ found that the dimensions of the FF nanotubes were strongly influenced not only by the temperature and $\mathrm{pH}$ but also by the ionic strength of the solution. Mba and co-workers ${ }^{[29]}$ synthetized two organogelators based on a pyrene moiety linked to FF that formed spherical aggregates and entangled fibrillary networks in acetonitrile and o-dichlorobenzene, respectively. Wang et al. ${ }^{[30]}$ used FF to prove that a trace amount of a solvent could be a predominant factor to tune the self-assembly of peptides. More specifically, these authors showed that the addition of very small amounts of solvents forced the formation of solvent-bridged hydrogen bonds, which was a crucial interaction in directing fiber formation.

In this paper, we use the solvent-mixing method (i.e. dissolving the peptide in an OS and adding water or another OS as a co-solvent) to examine the self-assembly of a new FF-based amphiphile. In this new compound, hereafter denoted TFA.FFOBzl (Scheme 1), the $C$ terminus is capped with a benzyl ester
(OBzl) group and the protonated amino group is stabilized to form an ion pair with trifluoroacetate (TFA). Accordingly, the aromatic interactions are expected to be weaker than those in Fmoc-FF, Nap-FF, and Fmoc-FF-OFm, whereas the dominant role played by intermolecular electrostatic interactions in FF is expected to decrease considerably because of the stability provided by TFA.<smiles>N[C@@H](Cc1ccccc1)C(=O)N[C@@H](Cc1ccccc1)C(=O)OCc1ccccc1</smiles>

Scheme 1. Chemical structure of TFA.FF-OBzl.

\section{Results and Discussion}

The results presented in this work correspond to the conditions under which repetitive, stable, and structured morphologies were observed. More specifically, assemblies were required to fulfill the following conditions: one, to present a clearly defined morphology; two, to be systematically observed if the same conditions are used in different and independent experiments; three, to remain formed upon manipulation for optical microscopy, scanning electron microscopy (SEM) and/or atomic force microscopy (AFM) observations.

\subsection{Peptide Synthesis and Preparation of Initial TFA.FF-OBzl Solutions}

The synthesis of TFA.FF-OBzl was performed by following the procedure provided in Figure 1.

As the main aim of this study was to investigate the influence of both the polarity of the medium and the peptide concentration in the assembly of TFA.FF-OBzl, a two-step proce-

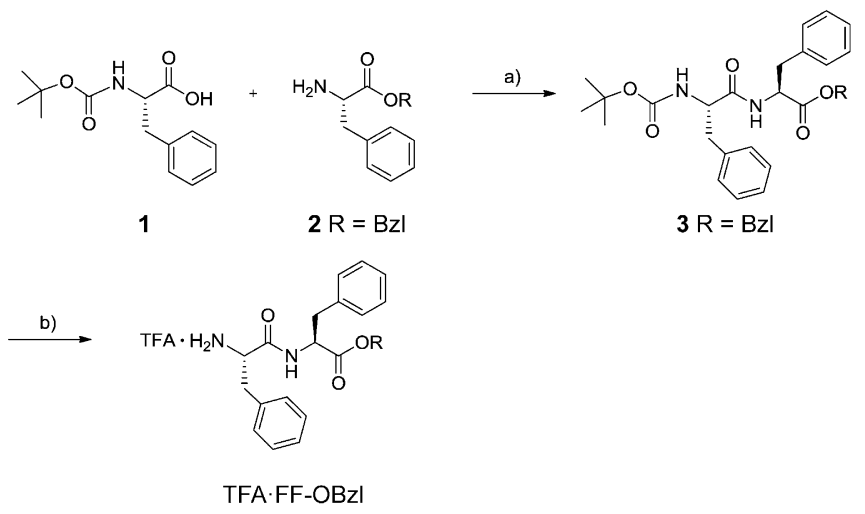

Figure 1. Scheme for the reactions used to obtain TFA.FF-OBzl. Reagents and conditions: a) $N$-[3-(dimethylamino)-propyl]- $N^{\prime}$-ethylcarbodiimide (EDC), 1-hydroxybenzotriazole ( $\mathrm{HOBt}$ ), $\mathrm{N}, \mathrm{N}$-diisopropylethylamine (DIPEA), $\mathrm{CH}_{2} \mathrm{Cl}_{2}$, $0^{\circ} \mathrm{C}, 30 \mathrm{~min}$, then RT, $24 \mathrm{~h}$; b) TFA, $\mathrm{CH}_{2} \mathrm{Cl}_{2}, \mathrm{RT}, 1 \mathrm{~h}$. 
dure was used. First, concentrated $\left(5.0 \mathrm{mg} \mathrm{mL}^{-1}\right)$ stock solutions were prepared by using solvent able to dissolve the peptide completely. For this purpose, four solvents with very different polarities were selected: hexafluoroisopropanol (HFIP), dimethylformamide (DMF), DMSO, and Milli-Q water. The dielectric constants of such solvents are: $\varepsilon=16.7$ (HFIP), 37.2 (DMF), 46.7 (DMSO), and 78.5 (water). Second, the peptide concentration and the polarity of the medium were altered by direct addition of a co-solvent to the stock solution. In addition to the abovementioned solvents, both methanol ( $\mathrm{MeOH}, \varepsilon=32.6)$ and chloroform $\left(\mathrm{CHCl}_{3}, \varepsilon=4.7\right)$, which are not able to dissolve the peptide completely, were considered as co-solvents. This procedure allowed the peptide concentration to be varied in the prepared solvent/co-solvent mixtures between 0.05 and $4.8 \mathrm{mg} \mathrm{mL}^{-1}$. Both the final peptide concentration and the chemical nature of the mixture will be provided for each discussed structure.

For the formation of the assembled structures, 10 or $20 \mu \mathrm{L}$ aliquots of the prepared peptide solutions were placed on microscope coverslips or glass slides (glass sample holders) and were kept at room temperature $\left(21^{\circ} \mathrm{C}\right)$ or inside a cold chamber $\left(4^{\circ} \mathrm{C}\right)$ until dryness. The humidity was kept constant in both laboratories at $50 \%$. Notably, no thermal treatment was applied to improve the solubility of the peptide or to accelerate the evaporation of the solvents. In spite of the huge number of conditions examined, the structures obtained under all of the conditions were carefully examined by optical microscopy. However, only those structures that fulfilled the requirements described above (i.e. well-defined morphology and reproducibility) were subsequently studied by SEM and AFM for discussion in this work.

\subsection{Aqueous Environment}

Dissolution of TFA.FF-OBzl into $2.0 \mathrm{mg} \mathrm{mL}^{-1} \mathrm{HFIP} /$ water (4:6) directed the self-assembly process towards peptide nanofibers with a diameter $(\phi)$ of about $250 \mathrm{~nm}$, and these nanofibers align and pack to form well-defined microfibers that have diameters up to roughly $10 \mu \mathrm{m}$ (Figure $2 \mathrm{a}$ ). At the same time, such microfibers form very dense aggregates with a spike-like morphology. As the polarity of the mixture increases and the peptide concentration decreases in $0.1 \mathrm{mg} \mathrm{mL}^{-1} \mathrm{HFIP} /$ water $(1: 49)$, the density of the aggregated microfibers decreases, whereas a very porous mesh of randomly oriented (bundled) fibers coexists that partially coats the spike-like supramolecular structure (Figure $2 \mathrm{~b}$ ). These bundled fibers exhibit very different diameters (i.e. from $\approx 100 \mathrm{~nm}$ to $\approx 1 \mu \mathrm{m}$ ) and do not present any kind of imperfection, as observed in the corresponding SEM and AFM images. The mesh is replaced by small needlelike crystals emerging from the spike-like microstructures in $1.0 \mathrm{mg} \mathrm{mL}^{-1}$ DMF/water (1:4) peptide solutions (Figure 2c). However, a remarkable difference is that such spikes are not formed by long aligned nanofibers, as observed in Figure $2 \mathrm{a}$ for the $2.0 \mathrm{mg} \mathrm{mL}^{-1} \mathrm{HFIP} /$ water (4:6) mixture, but by relatively short and sometimes broken interconnected nanofibers. These results suggest that the structure of the nanofibers, as well as their supramolecular organization (i.e. hierarchical self-assem-
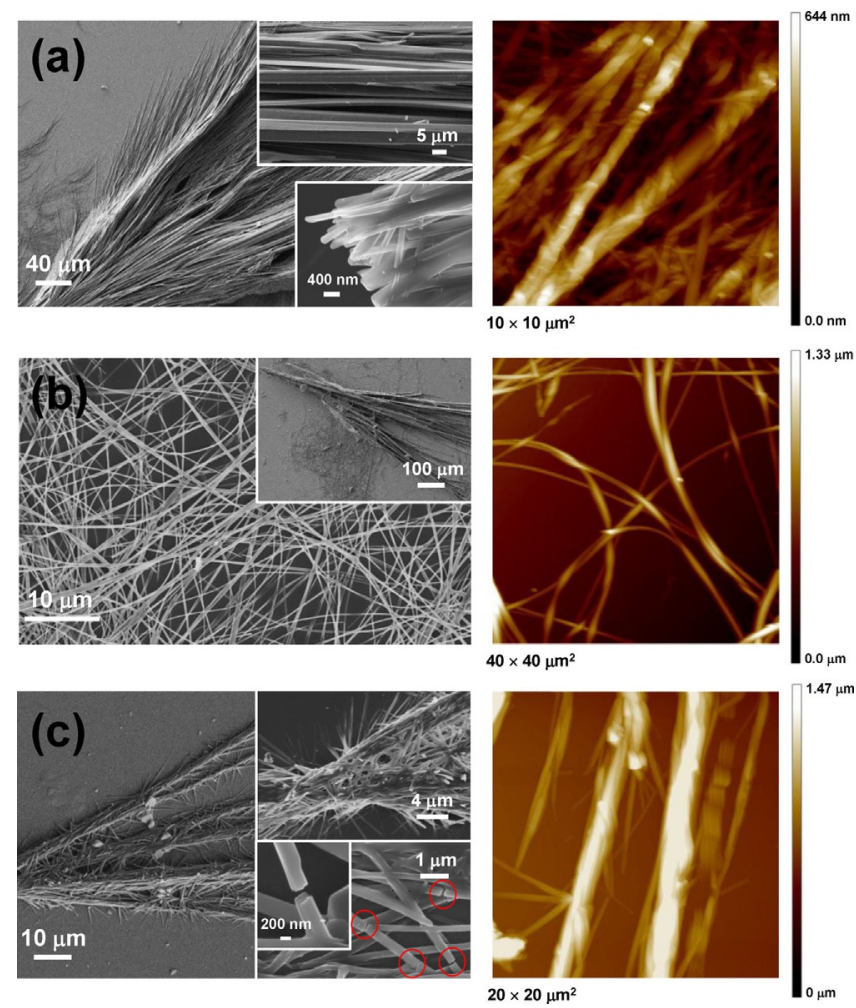

Figure 2. Representative SEM and AFM (height) images of the structures derived from TFA.FF-OBzl solutions in a) $2.0 \mathrm{mg} \mathrm{mL}^{-1} \mathrm{HFIP} /$ water $(4: 6)$ at $4{ }^{\circ} \mathrm{C}$, b) $0.1 \mathrm{mg} \mathrm{mL}^{-1} \mathrm{HFIP} /$ water (1:4) at room temperature, and c) $1.0 \mathrm{mg} \mathrm{mL}^{-1}$ DMF/water (1:4) at room temperature. The shape and hierarchical self-assembly change with the polarity of the solvent mixture and the peptide concentration. Red circles in panel c indicate broken nanofibers.

bly of TFA.FF-OBzl), change with both the polarity of the solvent mixture and the concentration of the peptide.

The addition of dilute $\mathrm{KCl}$ aqueous solutions ( $50 \mathrm{~mm}$ ) to the HFIP, DMF, and DMSO peptide solutions causes drastic morphological changes, which mainly consist in the apparition of branched-like structures and, in some cases, ultrathin plates. Thus, poorly defined micrometric branched-like architectures (Figure $3 \mathrm{a}$ ), which coexist with peptide microfibers (Figure S1 a, the Supporting Information), grow from $4.8 \mathrm{mg} \mathrm{mL}^{-1} \mathrm{HFIP}$ / $50 \mathrm{~mm} \mathrm{KCl} \mathrm{(24:1)} \mathrm{peptide} \mathrm{solutions.} \mathrm{However,} \mathrm{microfibers}$ coated with salt and with abundant defects (Figure S1 b) are the only structures observed upon reducing the peptide concentration to $1.0 \mathrm{mg} \mathrm{mL}^{-1}$. Furthermore, branched-like structures (Figure $3 \mathrm{~b}$ ), coexisting with disordered microfiber agglomerates (Figure S2), are obtained in $1.0 \mathrm{mg} \mathrm{m}^{-1} \mathrm{DMF}$ / $50 \mathrm{mM} \mathrm{KCl} \mathrm{(1:4).} \mathrm{The} \mathrm{branching} \mathrm{is} \mathrm{more} \mathrm{defined} \mathrm{than} \mathrm{that} \mathrm{in}$ Figure $3 \mathrm{a}$, which suggests that this class of architecture can be promoted by enhancing both the polarity of the mixture and the ionic force.

The large influence of polarity is corroborated in Figure $3 \mathrm{C}$ for the $4.8 \mathrm{mg} \mathrm{mL}^{-1} \mathrm{DMSO} / 50 \mathrm{~mm} \mathrm{KCl}$ (24:1) peptide mixture. In this case, well-defined branched structures, each one nucleating from a spherulite and partially coated with cubic crystals of salt, are abundantly detected. Both the central spherulite and the branches are made of ultrathin plates that, despite resembling lamellar crystal structures, are obtained through the 

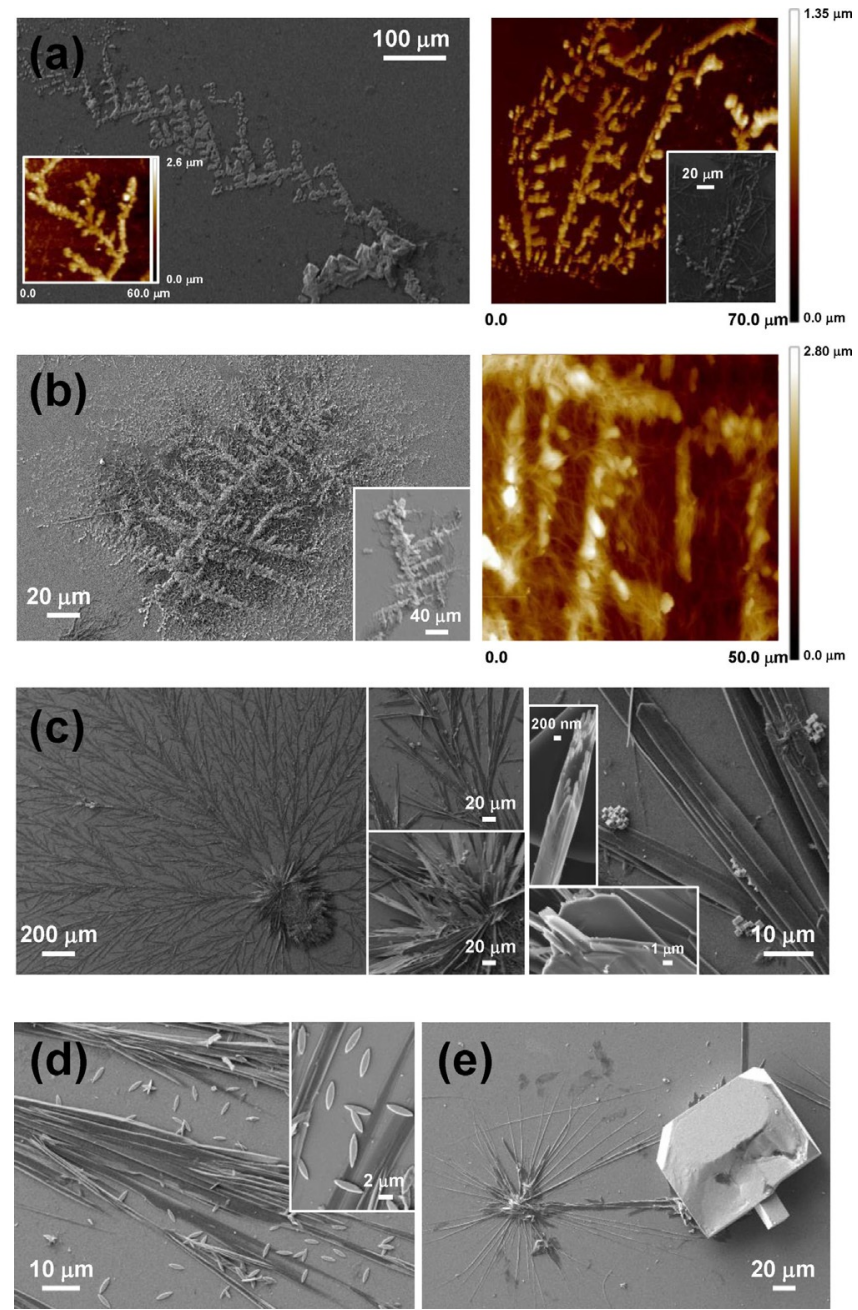

Figure 3. Representative SEM and AFM (height) images of the branched structures obtained at room temperature from TFA.FF-OBzl dissolved in a) $4.8 \mathrm{mg} \mathrm{mL}^{-1} \mathrm{HFIP} / 50 \mathrm{~mm} \mathrm{KCl}(24: 1)$, b) $1.0 \mathrm{mg} \mathrm{mL}^{-1} \mathrm{DMF} / 50 \mathrm{~mm} \mathrm{KCl}(1: 4)$, c) $4.8 \mathrm{mg} \mathrm{mL}^{-1} \mathrm{DMSO} / 50 \mathrm{~mm} \mathrm{KCl}(24: 1)$, d) $2.0 \mathrm{mg} \mathrm{mL}^{-1} \mathrm{DMSO} / 50 \mathrm{~mm} \mathrm{KCl}$ (4:6), and e) $0.25 \mathrm{mg} \mathrm{mL}^{-1} \mathrm{DMSO} / 50 \mathrm{~mm} \mathrm{KCl}(1: 19)$.

hierarchical assembly of nanowires. If the peptide concentration decreases to $2.0 \mathrm{mg} \mathrm{mL}^{-1}$ and, consequently, the polarity and ionic strength of the DMSO/50 $\mathrm{mm} \mathrm{KCl} \mathrm{(4:6)} \mathrm{mixture} \mathrm{in-}$ crease, branches become poorly defined and less abundant (Figure S3), even though the self-assembly characteristics are similar to those described above for the concentrated peptide solution. Moreover, these supramolecular structures coexist with randomly distributed micrometric crystals that are oval in shape (Figure $3 \mathrm{~d}$ ). Finally, if the peptide concentration is reduced, for example, in $0.25 \mathrm{mg} \mathrm{mL}^{-1} \mathrm{DMSO} / 50 \mathrm{mM} \mathrm{KCl} \mathrm{(1:19),}$ spherulitic-like microstructures surrounded by large salt crystals are observed (Figure $3 \mathrm{e}$ ). According to the micrographs displayed in Figures $3 \mathrm{C}-\mathrm{e}$ and $\mathrm{S} 3$, the combination of a polar OS (i.e. $\varepsilon=46.2$ for DMSO) with an aqueous salt solution, $\mathrm{KCl}_{(\mathrm{aq})}$, results in hierarchical assembly of the amphiphilic peptide under study, even though this tendency becomes less pronounced with decreasing amounts of DMSO (i.e. higher ionic strength). This feature should be associated with the influence of solvent molecules and salt ions on the balance between peptide-peptide and peptide-solvent interactions. The formation of branched-like structures is also considerably affected by the $\mathrm{pH}$. This is reflected in Figure S4, in which the $\mathrm{pH}$ of the corresponding $\mathrm{OS} / 50 \mathrm{mM} \mathrm{KCl}$ solutions was fixed at 10.5 by adding $0.5 \mathrm{M} \mathrm{NaOH}$. The poorly defined branched structures mentioned above for the $4.8 \mathrm{mg} \mathrm{mL}^{-1} \mathrm{HFIP} / 50 \mathrm{~mm} \mathrm{KCl}(24: 1)$ mixture (Figure $2 \mathrm{a}$ ) result in well-defined tree-like structures of a fibrous nature at basic pH values (Figure S4a). In contrast, the addition of $\mathrm{NaOH}$ transforms the spherulite-nucleated branches observed in Figure $2 \mathrm{c}$ into dense bundles of plates that are irregularly arranged (Figure $\mathrm{S} 4 \mathrm{~b}$ ). Indeed, some of these plates resemble deformed microtubes because of their dimensions. This is reflected by the AFM cross-sectional profile displayed in Figure $S 4 \mathrm{~b}$, which shows that the $x$ and $y$ diameters for one such element are around 2.3 and $2.0 \mu \mathrm{m}$, respectively. These changes are attributed to neutralization of the peptide by $\mathrm{NaOH}$. Thus, strong and nonspecific (nondirectional) electrostatic interactions associated with the charged end groups are probably replaced by weak and specific (directional) hydrogen bonds after neutralization, and these hydrogen bonds affect the definition of the assemblies their growing.

Notably, the branch- and tree-like structures obtained for TFA.FF-OBzl do not resemble the dendritic structures identified for $\mathrm{FF}^{[31]}$ and Fmoc-FFFF-Fmoc. ${ }^{[20]} \mathrm{Kim}$ and co-workers ${ }^{[31]}$ obtained highly ordered multidimensional dendritic nanoarchitectures by self-assembling FF from an acidic buffer solution. More recently, stable dendritic structures made of branches growing from nucleated primary frameworks were observed for Fmoc-FFFF-OFm. ${ }^{[20]}$ The fractal dimension of the FF and Fmoc-FFFF-OFm dendrimers was determined to be 1.7, which evidences self-similarity and two-dimensional diffusion-controlled growth. ${ }^{[20,31]}$ However, the branched and tree-like structures displayed in Figures 3 and $\mathrm{S} 4 \mathrm{a}$ do not exhibit a primary nucleating framework or a repetitive pattern for growth of the branches, which are essential to obtain the characteristic selfsimilarity of dendritic structures.

\subsection{Single Crystal X-ray Structure of TFA.FF-OBzl}

The X-ray diffractograms were collected for prism-like crystals obtained by slow evaporation of a $0.415 \mathrm{mg} \mathrm{mL}^{-1}$ solution of TFA.FF-OBzl in Milli-Q water at $80^{\circ} \mathrm{C}$. Table $\mathrm{S} 1$ summarizes the main crystallographic data of TFA.FF-OBzl, whereas Table S2 shows the final atomic parameters (fractional coordinates and thermal factors) together with the estimated standard deviations. Geometric parameters are listed in Tables S3 (bond lengths and angles) and Table S4 (torsional angles).

The conformation of a single TFA.FF-OBzl molecule is shown in Figure $4 \mathrm{a}$ together with labeling of atoms and the corresponding displacement ellipsoids. It is clear that the molecule adopts a folded conformation, and the peptide group is practically planar $\left(\mathrm{C} 10-\mathrm{N} 1-\mathrm{C} 1-\mathrm{C} 2-173.3^{\circ}\right)$ with $\varphi(\mathrm{C} 1-\mathrm{N} 1-\mathrm{C} 10-$ C11) and $\psi(\mathrm{N} 2-\mathrm{C} 2-\mathrm{C} 1-\mathrm{N} 1 / \mathrm{N} 1-\mathrm{C} 10-\mathrm{C} 11-\mathrm{O} 3)$ torsional angles of -86.6 and $127.7 /-54.9^{\circ}$, respectively. Notably, such a conformation does not fit to that expected for a conventional $\beta$ strand within a $\beta$ sheet, which typically exhibits $\varphi$ and $\psi$ values around -135 and $+135^{\circ}$. This feature is attributed to 
(a)

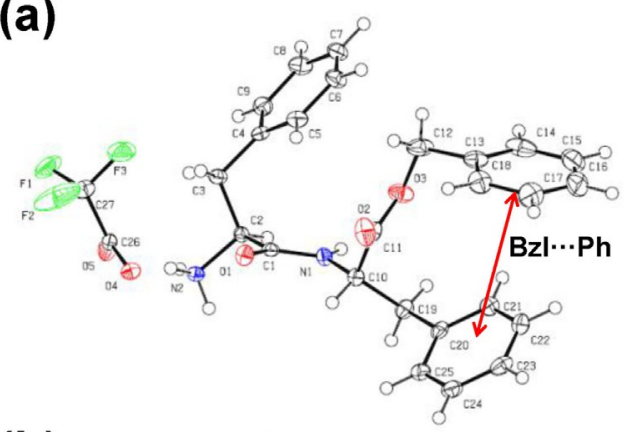

(b)

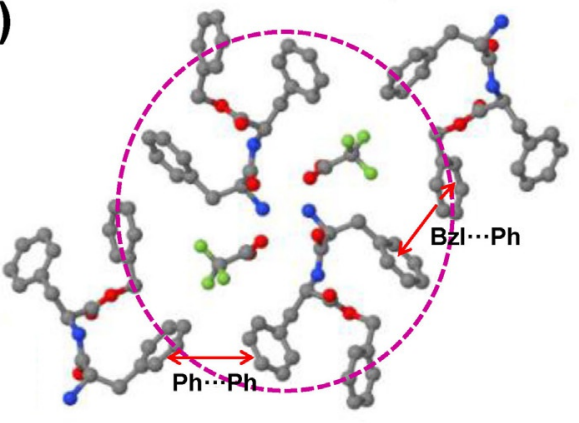

(c)

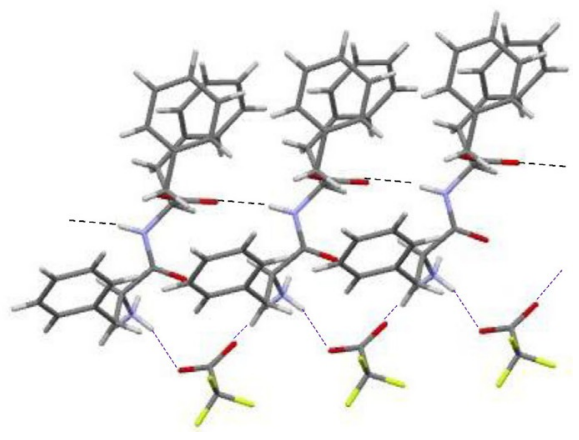

Figure 4. a) Scheme of the TFA.FF-OBzl molecule with displacement ellipsoids drawn at the $50 \%$ probability level. $\mathrm{H}$ atoms are drawn as circles with arbitrary radii. b) View along the $c$ axis showing the packing of two molecules related by a binary screw axis. Dashed circle points out the aromatic rings that are disposed around the inner hydrophilic part. $\mathrm{H}$ atoms are omitted for clarity. c) Scheme showing the intermolecular hydrogen bonds established between neighboring chains along the $a$ axis.

the formation of an intramolecular $\pi-\pi$ stacking interaction between the C13-C18 benzyl (Bzl) and C20-C25 phenyl (Ph) rings, which is indicated by a red arrow in Figure $4 \mathrm{a}$. The dihedral angle between the $\mathrm{Bzl}$ and $\mathrm{Ph}$ aromatic groups is $33.6^{\circ}$, whereas the distance between the centroids of the two rings is $4.59 \AA$.

TFA.FF-OBzl crystallizes in an orthorhombic unit cell containing four molecules (Figure S5) that are related by binary screw axes, as is typical of chiral organic molecules. Figure $4 \mathrm{~b}$ depicts a scheme of the molecular packing ( $b-c$ projection) with two neighboring molecules. The existence of a hydrophilic core, which is formed by the carboxylate (from TFA), ester, and amide groups, is particularly noticeable. This hydrophilic core is surrounded by a hydrophobic crown (dashed circle) formed by ten aromatic rings (i.e. six phenyl rings and four benzyl rings). Only six of these rings belong to the two represented molecules, whereas the other four are associated to neighbor- ing ones. Table S5 summarizes the hydrogen-bonding interactions that can be considered and that involve ester, amide, and carboxylate groups. The most relevant intermolecular hydrogen bond, which is formed along the $a$ direction, involves the $\mathrm{N}-\mathrm{H}$ (amide) and $\mathrm{C}=\mathrm{O}$ (ester) groups of molecules with a parallel orientation, as displayed in Figure $4 \mathrm{c}$. It is remarkable that the $\mathrm{C}=\mathrm{O}$ bond of the amide group only forms a weak interaction with terminal $\mathrm{NH}_{3}{ }^{+}$groups. Finally, intermolecular $\pi-\pi$ stacking interactions involving the $\mathrm{C} 4-\mathrm{C} 9(\mathrm{Ph}) . . \mathrm{C} 13-\mathrm{C} 18(\mathrm{Bzl})$ and $\mathrm{C} 4-\mathrm{C} 9(\mathrm{Ph}) . . \mathrm{C} 20-\mathrm{C} 25(\mathrm{Ph})$ aromatic rings are also present, and the distance between the centroids is around $4.5 \AA$.

Peptide...peptide intermolecular electrostatic, hydrogen bonds, and $\pi-\pi$ stacking interactions are known to be essential contributors to the formation of FF nano- and microarchitectures. ${ }^{[32]}$ According to its crystal structure, the importance of these intermolecular forces is maintained in the assembly of the TFA.FF-OBzl amphiphile. Thus, on the basis of the morphology of the assembled structures and on the positions of the molecules in the crystal structure reported in this work, as the solvent gradually evaporates, the individual TFA.FF-OBzl molecules tend to form intermolecular electrostatic and $\pi-\pi$ stacking interactions, which promotes the aggregation of peptide molecules and the formation of amphiphile crowns. The formation of a hydrophobic crown in the aggregates is reinforced by intramolecular $\pi-\pi$ stacking interactions. These interactions result in the formation of $\beta$-sheet structures, which stack vertically through hydrogen bonds, and this results in lengthening of the peptide structure. This process is similar to that reported for amyloid fibril formation, even though in that case aggregates were usually formed through electrostatic and hydrogen-bonding interactions (i.e. $\pi-\pi$ stacking interactions frequently participate in lengthening of the structure)..$^{[33]}$

\subsection{Organic Environment}

Dissolution of the peptide in a single OS resulted in a turbid solution with white particles (flocs) in suspension, and the combination of two OSs was necessary to obtain clear solutions and the subsequent self-assembly processes. Different levels of organization were obtained depending on the polarity of the mixture. Results are summarized in Figure 5.

Concentrated peptide solutions $\left(\geq 4 \mathrm{mg} \mathrm{mL}^{-1}\right)$ in polar organic mixtures, such as $\mathrm{DMF} / \mathrm{MeOH}$, result in well-defined microfibers ( $\phi$ ranging from 2.5 to $5.5 \mu \mathrm{m}$ ) with a smooth surface (Figure $5 \mathrm{a}$ ), and these microfibers tend to adopt a preferential alignment, crossed perpendicularly by fibers of smaller diameters $(\phi \approx 0.7-0.9 \mu \mathrm{m})$. Microfibers transform into microplates if the polarity of the environment decreases $\left(\geq 4 \mathrm{mg} \mathrm{mL}^{-1} \mathrm{HFIP}\right.$ / $\mathrm{MeOH})$, whereas crossed sub-microfibers change their perpendicular orientation for a tilted one $\left(\approx 45^{\circ}\right)$. Thus, the most remarkable feature caused by reducing the polarity is the branched-like supramolecular organization of the peptide (Figure $5 \mathrm{~b}$ ). This feature becomes more pronounced in the leastpolar environment $\left(4.0 \mathrm{mg} \mathrm{mL}^{-1} \mathrm{HFIP} / \mathrm{CHCl}_{3}\right)$, in which spherulitic-like structures made of microplates are frequently identified (Figure $5 \mathrm{c}$ ). 

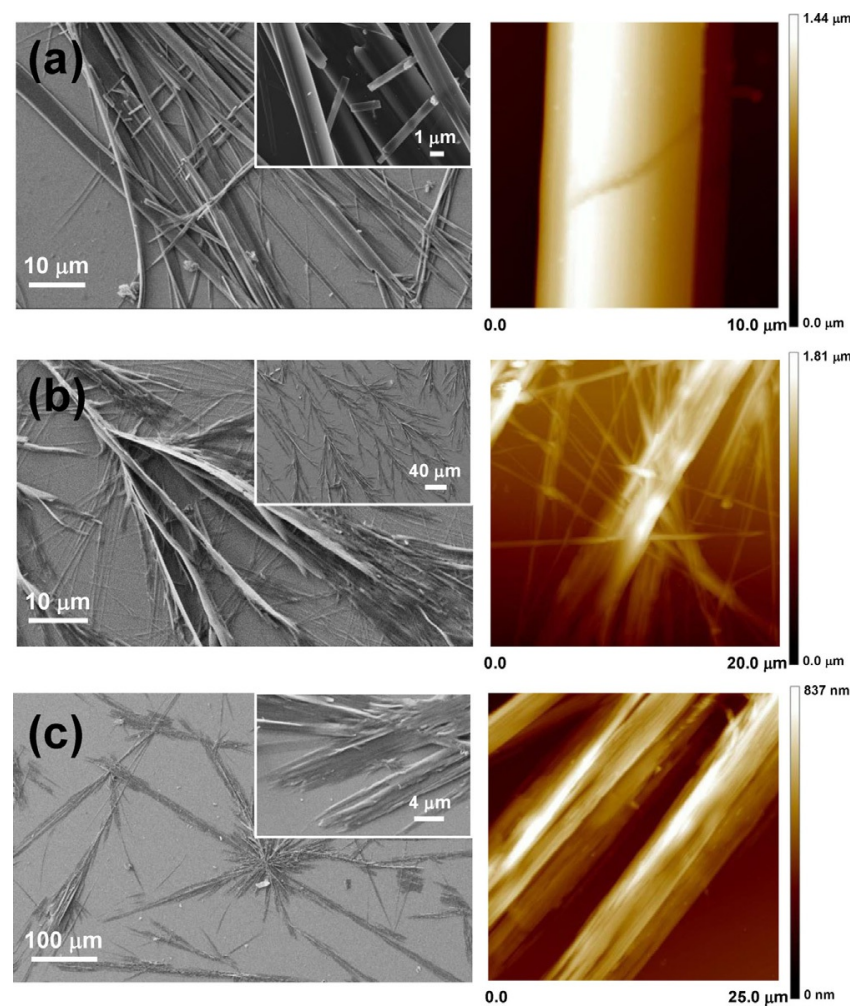

Figure 5. Representative SEM and AFM (height) images of the structures obtained at room temperature from TFA.FF-OBzl dissolved in a) $4.0 \mathrm{mg} \mathrm{mL}^{-1}$ $\mathrm{DMF} / \mathrm{MeOH}$, b) $4.0 \mathrm{mg} \mathrm{mL}^{-1} \mathrm{HFIP} / \mathrm{MeOH}$, and c) $4.0 \mathrm{mg} \mathrm{mL}^{-1} \mathrm{HFIP} / \mathrm{CHCl}_{3}$. Fiber-like organizations evolve into plate-like organizations with decreasing polarity of the medium. The dielectric constants of DMF, $\mathrm{HFIP}, \mathrm{MeOH}$, and $\mathrm{CHCl}_{3}$ are $\varepsilon=37.2,16.7,32.6$, and 4.7 , respectively.

Notably, structures obtained at low peptide concentrations are disordered (i.e. without a well-defined morphology) and are poorly reproducible in all cases. As a hypothesis, this can be attributed to the fact that the organization of the amphiphilic molecules forming hydrophobic crowns is difficult in organic solvents, which evaporate faster than water. Thus, a high amount of peptide molecules are presumably required to form regular structures with well-defined morphologies, such as those displayed in Figure 5.

Overall, the results obtained in OSs indicate that the polarity of the environment regulates the $3 D$ arrangement of the sheets formed by the TFA.FF-OBzl molecules, and it is this 3D arrangement that controls the formation of tubes or plates. On the other hand, comparison of the supramolecular organizations observed in aqueous solutions and OSs reflects two general trends that are characteristic of the latter environment. First, the concentration of the peptide required to obtain a well-defined self-assembly process in organic environments is significantly higher $\left(\geq 4 \mathrm{mg} \mathrm{mL}^{-1}\right)$ than that in aqueous solvents. Thus, in organic environments peptide-solvent interactions are energetically favored over peptide-peptide interactions. This suggests that in water-containing solutions (i.e. those with higher polarity), attractive interactions between polar groups and water are far from compensating the repulsive interactions between the solvent and the aromatic groups of the peptide. Second, the density of supramolecular struc- tures is considerably higher in water-containing environments than in OSs, which corroborates our previous hypothesis. Thus, the interaction of the peptide with the organic solvent is less repulsive than the interaction of the peptide with water, which hinders the self-assembly process in the former environment.

\subsection{Influence of the Surrounding Environment in the Assembly Mechanism}

The single-crystal structure of TFA.FF-Bzl, which was obtained by slow evaporation from a pure water solution, evidences the construction of a network of hydrogen bonds formed by parallel strands, which also interact through intra- and intermolecular stacking interactions (Figure 4). Although the parallel disposition of the molecules is in agreement with that observed by Adams and co-workers for single crystals of Fmoc-FF collected from gels formed in acetone, ${ }^{[18]}$ important differences are detected between the two structures. These differences correspond to the drastic separation between the hydrophilic and hydrophobic groups in TFA.FF-OBzl. Thus, TFA.FF-OBzl exhibits a hydrophobic crown surrounding a hydrophilic core that contains all of the polar groups, whereas this separation is much less pronounced in Fmoc-FF because of steric hindrance induced by the bulky Fmoc groups. ${ }^{[18]}$ The clear separation between the polar groups and the hydrophobic rings in TFA.FFOBzl facilitates understanding of the influence of the solvent on the morphology of the self-assembled aggregates. Thus, the crystal structure of TFA.FF-OBzl is considered representative to understand the behavior of amphiphilic FF-based biomaterials in different environments.

The obtainment of peptide nano- and microfibers in OS/ water environments with low and very low peptide concentrations (i.e. mixtures in which the high dielectric constant of water plays a dominant role because of its high volume ratio with respect to the OS) is attributed to an assembly in which hydrophobic and polar forces are equally important in promoting the longitudinal growth of the fiber, whereas the interactions between the fiber surface and both the environment and the glass support are stabilized by polar forces. Accordingly, the length of the fiber increases because of favorable hydrophobic-hydrophobic and polar-polar interactions between regions with identical natures, whereas polar groups remain exposed at the surface of the fibers (Figure $6 \mathrm{a}$ ). Moreover, this simple model explains that, for a given OS, the density of aggregated fibers decreases if the volume ratio of water as a cosolvent increases (i.e. the polarity of the mixture increases). Thus, the favorable interactions between the peptide polar groups and water molecules compensate the affinity between the surface polar groups of the different fibers if the concentration of water in the solvents mixture is high enough.

An enhancement in the ionic strength of the OS/water peptide solution, which is achieved by replacing Milli-Q water with a $50 \mathrm{~mm} \mathrm{KCl}$ aqueous solution as an added co-solvent, results in the formation of microstructures with branched-like architectures coexisting with continuous (nonbranched) fibers. The observation of cubic $\mathrm{KCl}$ crystals and a reduction in continuous fibers with increasing ionic strength are both consistent with 


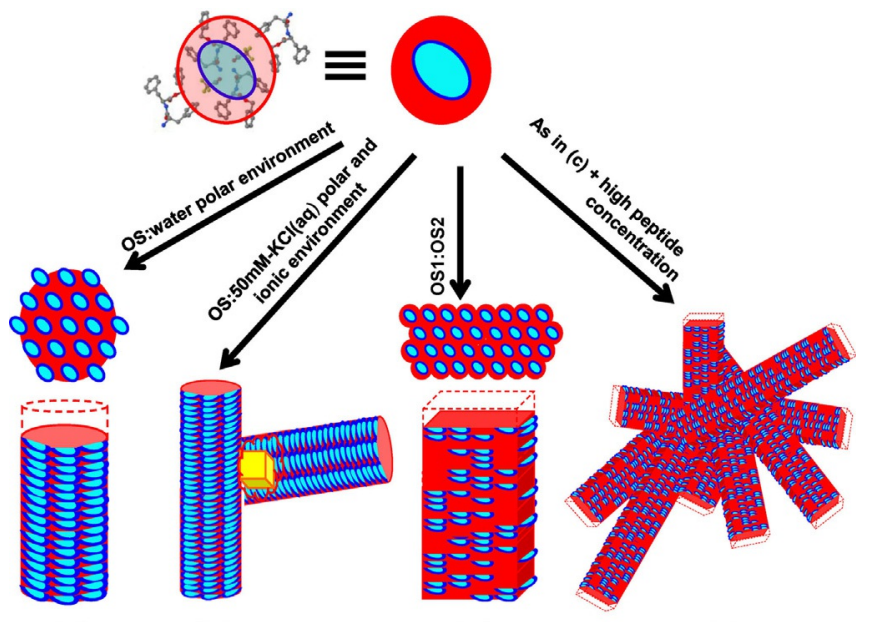

(a) (b) (d)

Figure 6. Schemes explaining the self-assembly and aggregation of TFA.FFOBzl under different conditions considering the hydrophilic (blue) and hydrophobic (red) regions observed in the corresponding X-ray structure (Figure 4): a) fibers, b) branched fibers, c) plates, and d) spherulites.

the mechanism displayed in Figure $6 \mathrm{~b}$. Accordingly, the salt nanocrystals coating the surface of the peptide fibers nucleate the branches that grow through favorable KCl...TFA.FF-OBzl electrostatic interactions. The frequency of this branching process increases with the ionic strength of the mixture, which explains the fact that the definition of the branched-like architectures and the presence of nonbranched fibers decrease with increasing volume ratios of $\mathrm{KCl}$ aqueous solution in the OS/COsolvent mixture.

Microstructures derived from the combination of two OSs also depend on the polarity of the mixture. Polar environments with high peptide concentrations result in the formation of microfibers by a mechanism similar to that displayed in Figure $6 a$, and they transform into microplates if the polarity of the environment decreases. To reduce access of the hydrophilic core to the surface, a mechanism such as that depicted in Figure $6 \mathrm{c}$ is proposed. In this mechanism, the $2 \mathrm{D}$ growth of the microstructure and the predominant hydrophobic region at the boundary favor the formation of peptide-solvent interactions. Moreover, as the polarity of the environment is not drastically low, the apparition of irregularities and defects with the hydrophilic core exposed to the solvent does not represent a severe thermodynamic penalty for generation of the microstructure. At high peptide concentrations, the affinity between the hydrophobic surface regions provokes aggregation of the plates, as is displayed in Figure $6 \mathrm{~d}$, which gives place to spherulites.

Overall, the results displayed in this work in combination with the straightforward models schematized in Figure 6 provide a simple rationale that explains the assembly behavior of the TFA.FF-OBzl amphiphile. Accordingly, the morphology of microstructures derived from this peptide can be easily regulated by controlling both the solvent and the peptide concentration. This versatility makes TFA.FF-OBzl a very interesting system for applications that are mainly based on interactions with other chemical species, for example, drugs. Within this

context, TFA.FF-OBzl microstructures are potential candidates to upload either polar or nonpolar drugs at their surface and, therefore, are potential candidates be used as versatile carriers and/or delivery systems. Thus, although some peptide amphiphiles have been previously suggested for delivery, ${ }_{r}^{[34,35]}$ their utility is typically restricted to the loading of polar or nonpolar drugs. However, the adaptability of TFA.FF-OBzl eliminates the restrictions related to the chemical nature of the used drugs, which gives a new dimension to this application.

\section{Conclusions}

We evidenced the remarkable control exerted by the characteristics of solvent mixtures on the organization of TFA.FF-OBzl (TFA = trifluoroacetate, $\quad F F=$ diphenylalanine,$\quad O B z l=$ benzyl ester) assemblies derived from the addition of a co-solvent to a peptide solution. Thus, the polarity, ionic strength, and peptide concentration in the mixture were regulated by adding a selected amount of a given co-solvent [i.e. pure water, $50 \mathrm{~mm}$ aq. $\mathrm{KCl}$, or an organic solvent (OS)] to a concentrated peptide solution in hexafluoroisopropanol (HFIP), DMF, DMSO, or water. Although polar aqueous environments tended to promote the growth of fibers, which were found to co-exist with branched-like microstructures if Milli-Q water was replaced by $50 \mathrm{~mm} \mathrm{KCl}$, nonpolar environments obtained by mixing two OSs preferred peptide assemblies organized in plates and spherulites.

The X-ray diffractograms collected for single crystals of TFA.FF-OBzl revealed a segregated distribution of the hydrophilic and hydrophobic regions. More specifically, the carboxylate (from TFA), amide, and ester (both from FF-OBzl) groups were separated from a highly polar core stabilized through hydrogen-bonding interactions, and this core was found to be ringed by a hydrophobic crown involving ten aromatic rings. This unique organization enabled us to explain the influence of the solvent mixture properties on peptide assembly. Thus, growth of the peptide structure and exposure of the hydrophilic or hydrophobic region were simply determined by the formation of favorable peptide-solvent interactions at the surface.

Tuning the structure of TFA.FF-OBzl by changing the solvents used in the mixture is a very attractive feature to expand the potential utility of peptide assemblies in different fields, for example, as molecular carriers and delivery systems. Thus, both polar and nonpolar compounds could be easily loaded on TFA.FF-OBzl microstructures by regulating the assembly through the solvents used in the mixture.

\section{Experimental Section}

\section{General Methods}

Melting points were determined with a Gallenkamp apparatus and are uncorrected. IR spectra were registered with a Nicolet Avatar 360 FTIR spectrophotometer; the $v_{\max }$ values are given for the main absorption bands. ${ }^{1} \mathrm{H}$ NMR and ${ }^{13} \mathrm{C}$ NMR spectra were recorded with a Bruker AV-400 or ARX-300 instrument at room temperature by using the residual solvent signal as the internal standard. 
Chemical shifts $(\delta)$ are expressed in ppm, and coupling constants $(J)$ are expressed in Hertz. Optical rotations were measured with a JASCO P-1020 polarimeter. High-resolution mass spectra were obtained with a Bruker Microtof-Q spectrometer.

\section{Peptide Synthesis and Characterization}

Boc-FF-OBzl (3): $\mathrm{HOBt} \cdot x \mathrm{H}_{2} \mathrm{O}(1.01 \mathrm{~g}, 6.6 \mathrm{mmol})$ was added to a solution of Boc-F-OH $(1 ; 1.75 \mathrm{~g}, 6.6 \mathrm{mmol})$ in dichloromethane $(15 \mathrm{~mL})$ cooled to $0^{\circ} \mathrm{C}$ in an ice bath, and this was followed by the addition of EDC. $\mathrm{HCl}(1.27 \mathrm{~g}, 6.6 \mathrm{mmol})$. The mixture was stirred for $15 \mathrm{~min}$, and then a solution of H-F-OR $2(6.0 \mathrm{mmol})$ [obtained by the addition of DIPEA (1.25 mL, $7.2 \mathrm{mmol})$ to the TFA salt of 2] in dichloromethane $(5 \mathrm{~mL})$ and additional DIPEA $(1.15 \mathrm{~mL}, 6.6 \mathrm{mmol})$ were added. The mixture was stirred for $1 \mathrm{~h}$ at $0^{\circ} \mathrm{C}$ and then at room temperature for $24 \mathrm{~h}$. The mixture was washed with $5 \%$ aq $\mathrm{NaHCO}_{3}(3 \times 15 \mathrm{~mL})$ and $5 \%$ aq. $\mathrm{KHSO}_{4}(3 \times 15 \mathrm{~mL})$. The organic phase was dried with anhydrous magnesium sulfate and evaporated to dryness. The resulting solid was suspended in a diethyl ether $/ n$-hexane mixture and was filtered under reduced pressure to provide 3 as a white solid. Yield: $90 \%$; m.p. $180-181^{\circ} \mathrm{C} ;[\alpha]_{D}^{25}=$ $-17.7\left(c=0.33\right.$ in methanol); ${ }^{1} \mathrm{H}$ NMR $\left(400 \mathrm{MHz}, \mathrm{CDCl}_{3}\right): \delta=1.32(\mathrm{~s}$, $9 \mathrm{H}), 2.92-3.02(\mathrm{~m}, 4 \mathrm{H}), 4.21-4.30(\mathrm{~m}, 1 \mathrm{H}), 4.72-4.76(\mathrm{~m}, 1 \mathrm{H}), 4.86$ (brs, 1H), $5.02(\mathrm{~s}, 2 \mathrm{H}), 6.20(\mathrm{~d}, J=7.6 \mathrm{~Hz}, 1 \mathrm{H}), 6.81-6.83(\mathrm{~m} 2 \mathrm{H})$, 7.07-7.14 $(\mathrm{m}, 5 \mathrm{H}), 7.16-7.21(\mathrm{~m}, 5 \mathrm{H}), 7.26-7.32 \mathrm{ppm}(\mathrm{m}, 3 \mathrm{H})$; ${ }^{13} \mathrm{C} \mathrm{NMR}\left(100 \mathrm{MHz}, \mathrm{CDCl}_{3}\right): \delta=28.36,38.07,38.43,53.44,55.82$, $67.35,80.32,127.11,127.19,128.65,128.67,128.70,128.74,128.79$, $129.41,129.49,135.14,135.61,136.62,155.39,170.85,170.90$ ppm; IR (KBr): $\tilde{v}=3332,1741,1696,1681 \mathrm{~cm}^{-1}$; HRMS (ESI): $\mathrm{m} / \mathrm{z}$ : calcd for $\mathrm{C}_{30} \mathrm{H}_{34} \mathrm{~N}_{2} \mathrm{NaO}_{5}: 525.2360[\mathrm{M}+\mathrm{Na}]^{+}$; found: 525.2375 .

For tert-butoxycarbonyl (Boc) deprotection, a solution of the corresponding Boc-protected compound in dichloromethane was treated with trifluoroacetic acid (TFA-H; 15 equiv.), and the mixture was stirred at room temperature for $1 \mathrm{~h}$. After evaporation of the solvent, the residue was suspended in a diethyl ether $/ n$-hexane mixture and filtered under reduced pressure to provide the corresponding TFA salt as a white solid in quantitative yield.

TFA.FF-OBzl (4): According to the general Boc-deprotection procedure, TFA $(2 \mathrm{~mL})$ was added to a solution of $3(2.0 \mathrm{mmol})$ in dichloromethane $(20 \mathrm{~mL})$ to provide corresponding TFA salt 4 (Figure S6) in quantitative yield. M.p. $290-292^{\circ} \mathrm{C}$ (decomp.); $[\alpha]_{D}^{20}=$ $+18.2\left(c=0.36\right.$ in acetic acid); ${ }^{1} \mathrm{H}$ NMR $\left(400 \mathrm{MHz},\left[\mathrm{D}_{6}\right] \mathrm{DMSO}: \delta=\right.$ 2.90 (dd, $J=14.2 \mathrm{~Hz}, J=8.3 \mathrm{~Hz}, 1 \mathrm{H}$ ), 3.02 (dd, $J=13.9 \mathrm{~Hz}, J=8.1 \mathrm{~Hz}$, $1 \mathrm{H}), 3.08-3.13(\mathrm{~m}, 2 \mathrm{H}), 4.05-4.13(\mathrm{~m}, 1 \mathrm{H}), 4.63-4.69(\mathrm{~m}, 1 \mathrm{H}), 5.06-$ $5.14(\mathrm{~m}, 2 \mathrm{H}), 7.22-7.38(\mathrm{~m}, 15 \mathrm{H}), 8.23(\mathrm{brs}, 2 \mathrm{H}), 9.15 \mathrm{ppm}(\mathrm{d}, J=$ $7.5 \mathrm{~Hz}, 1 \mathrm{H}) ;{ }^{13} \mathrm{C}$ NMR $\left(100 \mathrm{MHz},\left[\mathrm{D}_{6}\right] \mathrm{DMSO}\right): \delta=36.79,36.99,53.21$, $54.03,66.37,111.85,114.77,117.68,120.60,126.80,127.19,128.09$, $128.20,128.45,128.54,129.18,129.59,134.79,135.60,136.65$, $158.05,158.40,158.75,159.10,168.43,170.71 \mathrm{ppm} ; \mathrm{IR}(\mathrm{KBr}): \tilde{v}=$ 3342, 1725, 1695, $1662 \mathrm{~cm}^{-1}$; HRMS (ESI): $\mathrm{m} / \mathrm{z}$ : calcd for $\mathrm{C}_{25} \mathrm{H}_{26} \mathrm{~N}_{2} \mathrm{NaO}_{3}$ : $425.1836[\mathrm{M}+\mathrm{Na}]^{+}$; found: 425.1821 .

\section{Sample Preparation}

Peptide-containing solutions ( 25 or $100 \mu \mathrm{L}$ ) were prepared from $5 \mathrm{mg} \mathrm{mL}^{-1}$ stock solutions by using HFIP, DMF, DMSO, and Milli-Q water as solvents. The peptide concentration was reduced by adding Milli-Q water, $\mathrm{MeOH}$, or $\mathrm{CHCl}_{3}$ as co-solvent to a given stock solution. More specifically, peptide concentrations of 4.8, 4.0, 2.0, 1.0, $0.3,0.25$, and $0.1 \mathrm{mg} \mathrm{mL}^{-1}$ were obtained by using $24: 1$, $4: 1,4: 6,1: 4,3: 47,1: 19$, and 1:49 solvent/co-solvent ratios, respectively. On the other hand, the $50 \mathrm{~mm}$ aq. $\mathrm{KCl}$ solution was used as a co-solvent to modify the ionic strength. Finally, 10 or $20 \mu \mathrm{L}$ aliquots were placed on microscope coverslips and kept at room temperature $\left(25^{\circ} \mathrm{C}\right)$ or inside a cold chamber $\left(4^{\circ} \mathrm{C}\right)$ until dryness. All organic solvents were purchased from Sigma-Aldrich, Fisher Scientific, and Scharlab.

\section{Optical Microscopy}

Morphological observations were performed by using a Zeiss Axioskop 40 microscope. Micrographs were taken with a Zeiss AxiosCam MRC5 digital camera.

\section{Scanning Electron Microscopy (SEM)}

SEM studies were performed with a Focussed lon Beam Zeiss Neon 40 scanning electron microscope operating at $5 \mathrm{kV}$ and equipped with an EDX spectroscopy system. Samples were mounted on a double-sided adhesive carbon disc and were sputter coated with a thin layer of carbon to prevent sample charging problems.

\section{Atomic Force Microscopy (AFM)}

Topographic AFM images were obtained by using either a Dimension 3100 Nanoman AFM or a Multimode, both from Veeco (NanoScope IV controller), under ambient conditions in tapping mode. AFM measurements were performed on various parts of the morphologies, which produced reproducible images similar to those displayed in this work. Scan window sizes ranged from $5 \times 5$ to $80 \times 80 \mu \mathrm{m}^{2}$.

\section{Crystallization and X-ray Diffraction}

Colorless prism-like crystals $(0.010 \mathrm{~mm} \times 0.020 \mathrm{~mm} \times 0.100 \mathrm{~mm})$ were obtained by slow evaporation at $80^{\circ} \mathrm{C}$ of a $0.415 \mathrm{mg} \mathrm{mL}^{-1}$ solution of TFA.FF-OBzl in MQ-grade water and were used for X-ray diffraction analysis. The X-ray intensity data were measured with a D8 Venture system equipped with a multilayer monochromator and a Cu microfocus $(\lambda=1.54178 \AA$ ).

The frames were integrated with the Bruker SAINT software package by using a narrow-frame algorithm. Integration of the data using an orthorhombic unit cell yielded a total of 13671 reflections to a maximum $\theta$ angle of $79.25^{\circ}$ ( $0.78 \AA$ resolution), of which 5037 were independent (average redundancy 2.714, completeness = $\left.95.0 \%, R_{\text {int }}=4.97 \%, R_{\text {sig }}=5.67 \%\right)$ and $4499(89.32 \%)$ were greater than $2 \sigma\left(F^{2}\right)$. The final cell constants of $a=5.8856(3) \AA, b=$ 18.5677(9) $\AA, c=23.0370(11) \AA$, and volume $=2517.5(2) \AA^{3}$ are based upon the refinement of the $x y z$ centroids of reflections above $2 \theta \sigma(l)$. Data were corrected for absorption effects by using the multiscan method (SADABS). The calculated minimum and maximum transmission coefficients (based on crystal size) are 0.6156 and 0.7461 .

The structure was solved and refined by using the Bruker SHELXTL software package by using the $P 2_{1} 2_{1} 2_{1}$ space group with $Z=4$ for the formula unit, $\mathrm{C}_{27} \mathrm{H}_{27} \mathrm{~F}_{3} \mathrm{~N}_{2} \mathrm{O}_{5}$. The final anisotropic full-matrix least-squares refinement on $F^{2}$ with 335 variables converged at $R 1=4.26 \%$ for the observed data and $w R 2=14.04 \%$ for all data. The goodness-of-fit was 1.032. The largest peak in the final difference electron density synthesis was $0.289 \mathrm{e}^{-3}$, and the largest hole was $-0.257 \mathrm{e} \AA^{-3}$ with a root-mean square deviation of 
$0.059 \mathrm{e} \AA^{-3}$. On the basis of the final model, the calculated density was $1.363 \mathrm{~g} \mathrm{~cm}^{-3}$ and $F(000)$ was $1080 \mathrm{e}$

\section{Acknowledgements}

The authors are thankful for support from MINECO and FEDER (MAT2015-69367-R, MAT2015-69547-R and CTQ2013-40855-R) and Gobierno de Aragón-Fondo Social Europeo (research group E40). Support for the research of C.A. was received through the prize "ICREA Academia" for excellence in research funded by the Generalitat de Catalunya.

\section{Conflict of interest}

The authors declare no conflict of interest.

Keywords: fibers · hydrophilic core $\cdot$ nanostructures $\cdot$ peptide materials $\cdot$ stacking interactions

[1] M. Reches, E. Gazit, Science 2003, 300, 625-627.

[2] P. Tamamis, L. Adler-Abramovich, M. Reches, K. Marshall, P. Sikorski, L. Serpell, E. Gazit, G. Archontis, Biophys. J. 2009, 96, 5020-5029.

[3] C. H. Görbitz, Chem. Commun. 2006, 2332-2334.

[4] L. Adler-Abramovich, M. Reches, V. L. Sedman, S. Allen, S. J. B. Tendler, E. Gazit, Langmuir 2006, 22, 1313-1320.

[5] M. Reches, E. Gazit, Phys. Biol. 2006, 3, S10-S19.

[6] M. Reches, E. Gazit, Nano Lett. 2004, 4, 581-585.

[7] E. Mayans, G. Ballano, J. Casanovas, A. Díaz, A. Pérez-Madrigal, F. Estrany, J. Puiggalí, C. Cativiela, C. Alemán, Chem. Eur. J. 2015, 21, 16895-16905.

[8] X. Yan, J. Li, H. Möhwald, Adv. Mater. 2011, 23, 2796-2801.

[9] J. Raeburn, A. Zamith Cardoso, D. J. Adams, Chem. Soc. Rev. 2013, 42, 5143-5156.

[10] A. Mahler, M. Reches, M. Rechter, S. Cohen, E. Gazit, Adv. Mater. 2006 $18,1365-1370$

[11] N. Amdursky, R. Orbach, E. Gazit, D. Huppert, J. Phys. Chem. C 2009, 113, $19500-19505$.

[12] V. Jayawarna, M. Ali, T. A. Jowitt, A. F. Miller, A. Saiani, J. E. Gough, R. V. Ulijn, Adv. Mater. 2006, 18, 611-614.

[13] A. M. Smith, R. J. Williams, C. Tang, P. Coppo, R. F. Collins, M. L. Turner, A. Saiani, R. V. Ulijn, Adv. Mater. 2008, 20, 37-41.
[14] C. Tang, A. M. Smith, R. F. Collins, R. V. Ulijn, A. Saiani, Langmuir 2009, $25,9447-9453$

[15] M. Zhou, A. M. Smith, A. K. Das, N. W. Hodson, R. F. Collins, R. V. Ulijn J. E. Gough, Biomaterials 2009, 30, 2523-2530.

[16] J. Raeburn, G. Pont, L. Chen, Y. Cesbron, R. Levy, D. J. Adams, Soft Matter 2012, 8, 1168-1174.

[17] N. A. Dudukovic, C. F. Zukoski, Langmuir 2014, 30, 4493-4500.

[18] J. Raeburn, C. Mendoza-Cuenca, B. N. Cattoz, M. A. Little, A. E. Terry, A. Z. Cardoso, P. C. Griffiths, D. J. Adams, Soft Matter 2015, 11, 927-935

[19] V. Jayawarna, A. Smith, J. E. Gough, R. V. Ulijn, Biochem. Soc. Trans. 2007 35, 535-537.

[20] E. Mayans, G. Ballano, J. Casanovas, L. J. del Valle, M. M. Pérez-Madrigal, F. Estrany, A. I. Jiménez, J. Puiggalí, C. Cativiela, C. Alemán, Soft Matter 2016, 12, 5475-5488

[21] P. W. J. M. Frederix, R. Kania, J. A. Wright, D. A. Lamprou, R. Ulijn, C. J. Pickett, N. T. Hunt, Dalton Trans. 2012, 41, 13112-13119.

[22] W. Helen, P. de Leonardis, R. V. Ulijn, J. Gough, N. Tirelli, Soft Matter 2011, 7, $1732-1740$.

[23] V. Jayawarna, S. M. Richardson, A. R. Hirst, N. W. Hodson, A. Saiani, J. E. Gough, R. V. Ulijn, Acta Biomater. 2009, 5, 934-943.

[24] Y. Yamauchi, M. Yoshizawa, M. Fujita, J. Am. Chem. Soc. 2008, 130 $5832-5833$

[25] K. V. Rao, S. J. George, Chem. Eur. J. 2012, 18, 14286-14291.

[26] P. Zhu, X. Yan, S. Su, Y. Yang, J. Li, Chem. Eur. J. 2010, 16, 3176-3183.

[27] R. Huang, W. Qi, R. Su, J. Zhao, Z. He, Soft Matter 2011, 7, 6418-6421.

[28] P. Kumaraswamy, R. Lakshmanan, S. Sethuraman, U. M. Krishnan, Soft Matter 2011, 7, 2744-2754.

[29] S. Bartocci, I. Morbioli, M. Maggini, M. Mba, J. Pept. Sci. 2015, 21, 871 878.

[30] J. Wang, K. Liu, L. Yan, A. Wang, S. Bai, X. Yan, ACS Nano 2016, 10, $2138-2143$.

[31] T. H. Han, J. K. Oh, G.-J. Lee, S. I. Pyun, S. O. Kim, Colloids Surf. B 2010, $79,440-445$.

[32] C. H. Gorbitz, Chem. Eur. J. 2001, 7, 5153-5159.

[33] X. Yan, P. Zhu, J. Li, Chem. Soc. Rev. 2010, 39, 1877-1890.

[34] V. Castelletto, J. E. McKendrick, I. W. Hamley, U. Olsson, C. Cenker, Langmuir 2010, 26, 11624-1162.

[35] S. T. Kumar, J. Meinhardt, A. K. Fuchs, T. Aumüller, J. Leppert, B. Büchele, U. Knüpfer, R. Ramachandran, J. K. Yadav, E. Prell, I. Morgado, O. Ohlenschläger, U. Horn, T. Simmet, M. Görlach, M. Fändrich, ACS Nano 2012, 8, 11042-11052.

Manuscript received: February 18, 2017

Revised manuscript received: March 17, 2017

Accepted manuscript online: April 4, 2017

Version of record online: May 18, 2017 